\title{
A generic change model for the effective implementation of information systems
}

\author{
K.E. Jay \\ Project Leader, Shell South Africa, P.O. Box 2231, Cape Town, 8001 Republic of South Africa \\ Internet: kjay@cssa.org.za \\ D.C. Smith* \\ Department of Information Systems, University of Cape Town, Rondebosch, 7700 Republic of South Africa \\ Internet: derek@INFOSYS.UCT.AC.ZA
}

Received April 1996

\begin{abstract}
This article describes the need for an increased emphasis for change management and how it affects the information systems (IS) practitioner. Computer-based systems have become highly integrated into everyday business activities and the successful implementation of new information technology will depend upon not only the technical strength of the information system but, importantly, the effective management of organizational change. Organizational change issues are identified as planning for change, ensuring appropriate change leadership, creating a readiness for change, managing resistance to change, managing the transition, implementing and evaluating the change. A conceptual change model is derived for use in a systems development environment. This model proposes four main phases: orientation, preparation, implementation and support. Specific activities and deliverables are detailed for each segment. The proposed change model is matched to the Systems Development Life Cycle, showing where change management tasks could be incorporated into an overall project workplan.
\end{abstract}

*To whom correspondence should be addressed.

'Change' is a word that creates stress in the business world. According to Charles Handy, a business philosopher, change is not what it used to be (1995: 4). He feels that, if we are to maximize opportunity and minimize risk, we must understand change better. He also feels that those who understand why change has to occur, will waste less effort in protecting themselves from the change or in resisting the inevitable. In a positive light, he argues that 'change is ... another word for growth, another synonym for learning' (Handy, 1995: 5).

According to Strebel (1994), chief executives are putting their companies through radical restructuring with little account being taken of the time and process needed to change skills or behaviour. Managing organizational change has been continuously addressed since Lewin developed his 'unfreeze - change - refreeze' model in 1958 (Burke, 1987). Computerbased systems are becoming highly integrated into everyday business activities, and information technology (IT) is often used to assist with the change management process (McKersie \& Walton, 1991). According to Benjamin \& Blunt (1992), 'IT executives need to ... be the champions for technologyenabled change'.

An increased focus on change management is vital for the successful implementation of new information systems. This article reviews aspects of change leadership and change models and their relevance to the Information Systems (IS) industry. A comprehensive, generic change model is proposed. This model is mapped onto a typical systems development life-cycle model (SDIC) to provide information systems (IS) managers with the essential steps required to ensure change management has increased focus in the development process.

\section{Organizational change and change models}

Bridges (1991) identified the main issues of change as unlearning the old system and learning something new; as unlearning old attitudes and values and changing people; and as motivating changes through a multi-stage process. The process is very people-oriented.
If a change is to yield the desired results, it must be managed. If it is to be managed, it must be understood. Bridges (1991) describes passing from one state to another as the transition process. He describes this process as one that involves leaving behind the old reality and it's value systems, beliefs and behaviours. As one situation ends, another begins. The period between the old and the new is the 'neutral zone'. It is in this stage that creativity, renewal and revitalization form the core of the transition process, and shape the future direction. Many authors warn that the cost of not managing the transition correctly can result in guilt, resentment, anxiety, stress and ultimately a negation of the benefits the change was designed to yield.

Most models of change seem to regard change initiatives as projects within themselves, with definitive beginning and end points. This concept may work if the entire scope of the project is limited to achieving change. With IS-driven projects, or even those projects where IS is required to enable or support a business initiative, the change cycle must be related to either the Project Management or Systems Development Life Cycle.

\section{Key organizational change issues}

Key areas of change management are planning for change, ensuring appropriate change leadership, creating a readiness for change, managing resistance to change, managing the transition, implementing the change, and finally, evaluating change. The key tool for planning is the project workplan. Individual tasks should detail the steps that deal with the human side of change, as well as task-oriented functions. Change can be viewed at the organizational level (the macro level) or at the individual level (the micro level). Depending on the response of people to the change, the micro element of change may lead to the success or destruction of the change. The impact on people needs recognition, analysis and careful 
planning. Grundy \& King (1992) warn that the communication process takes as much planning as the initial change plan.

Schaffer \& Thomson (1992) and McKersie \& Walton (1991) concur that successful change programmes begin with a statement of expected results. Any change that is introduced should have a very specific goal. Both ODR (1991) and Bridges (1991) stress the need to address how individual behaviour and attitudes will have to change. In selecting a change strategy, a manager should determine whether the approach used will be participative or directive. Participative change is more successful in the long term because of the resulting people buy-in and commitment. It may, however, take significantly longer to plan and implement the change using this approach. A directive change, imposed from the 'top', may be achieved in a much shorter time-frame, but it may create animosity and covert, undermining behaviour. The manager, acting as a change agent, must decide which style is appropriate for the situation. In reality, a combination may be appropriate, but care must be taken to ensure the 'balance' is not just notional. Changes are best brought about through middle managers, not top managers. Although middle managers are often reluctant to change, once they are convinced of the need and advantages of change, they become the advocates of change who are best positioned to effect the change (Nichol, 1992). The role of the manager through a major change may be a difficult one (Kissler: 1991). Managers are normally viewed as having influence over events and staff look to them for protection and assurance. Managers have to accept responsibility for the change and provide support to those who will be impacted. In addition, managers require diagnostic and implementation skills to plan and implement the change (Hersey \& Blanchard, 1982).

But managers cannot implement successful changes in isolation. Rochester (1990) identifies the other key players as the sponsors, targets, champions and advocates of the change. The sponsor gives legitimacy to the change process. It is essential that the sponsor is committed to the change and believes the change is necessary for survival. ODR (1991) develop this concept further by advocating sustaining sponsors as well as initiating sponsors. Sustaining sponsors would typically be in middle-management positions and would be responsible for sustaining the change momentum. Sponsor commitment must be planned for and built early in the change cycle. Sponsors will then be positioned to create an environment where affected staff are adequately prepared.

Although pressure for change often occurs when an organization no longer responds to competitive or organization requirements, promoting the need for change requires the action of creating pain. ODR identify 'pain management' as:

'the key process of consciously surfacing and orches-

trating certain information in order to generate the appropriate level of pain to discontinue the status quo (1991: 31).

The need to create pain, 'discomfort' or 'dissatisfaction' is probably the most widely covered subject in Change Management literature. Discomfort and dissatisfaction are seldom enough to motivate change. Spector (1989) suggests that dissatisfaction can be diffused by sharing information to unfreeze attitudes; by conducting regular staff opinion surveys; and by using selected pilot sites where success will lead to other sites becoming more receptive to change. The intention of creating pain is to make the people affected by the change accept that they are part of the problem, so that they share the responsibility for the consequences. They then participate in identifying and implementing the changes needed (Pearce \& Robinson, 1989). The buy-in has two stages: logical and emotional. The logical buy-in involves an understanding of the facts and implications. The emotional buy-in involves a person's own plan for instituting the change, and the identfication of the advantages to the individual (Nichol, 1992).

Managing resistance to change is possibly the most researched area of change leadership. Change management must ensure that all sponsors, change agents and targets move through the cycle as quickly as possible, without forcing the next stage. Forced progression will result in unhealed scars which will surface later and possibly undermine the change success (Bridges, 1991). Pearce and Robinson (1989) identify the reasons and explanations for resistance to change as uncertainty, lack of trust, self-interest and differing opinions. They advocate the adoption of a contingency approach to change management depending on the reason for the change. For example, a communication and education approach is used when the change is not fully understood and job content is likely to change dramatically, whereas a coercion approach could be used when time is short and other approaches have failed.

Implementing the change is the process of rolling out the change plan. Duberly \& Burns (1992) describe the success areas for implementing change as the content, the context and the process. They claim that people have to understand, believe in and have a common view of the purpose of the change. It is necessary to communicate with all the parties likely to be affected by the change. They feel that it is important to explain why the change is being introduced and what constraints apply. In terms of the process, communication should be used to gain the support of the work force before the implementation begins. ODR (1991) view sponsorship as the key to the implementation of change. They recommend that weak sponsors must be educated or replaced to avoid failure. Sponsorship cannot be delegated as the sponsor must be the person who holds legitimization power. Where implementation was phased over multiple sites, Kissler (1991) found that the last site to convert benefited from the time spent and experience gained from previous changes.

Finally, evaluating change is the step often neglected and which may provide the key for 'relapse prevention' (Herzog, 1991). It cannot be assumed that the new change will continue as it was planned or envisaged. Change opposers will try to revert to the old system thus reducing or destroying any benefits of the change. Staff turnover can also cause lack of continuity, and the change may be ineffective through lack of appropriate training for replacement staff.

Schein (1980) suggests that interim goals should be set throughout the change cycle. These goals should be evaluated during the transition - not only at the end of the change implementation. Finkin (1992) recommends that positive reinforcement and feedback are used to show what is expected in the new culture. He explains that it usually takes up to five years for a new corporate culture to completely replace the 
practices of the old culture. Grundy \& King (1992) propose that change is a one-way ticket and organizations can never go back without being worse off.

\section{Consolidated change model}

Four clear phases have been identified in a change model the initial orientation, the preparation phase, implementation of the change and a supportive phase. An analysis of change models in the literature identified several key activities and deliverables within these phases (Herzog, 1991; Schein, 1980; Andersen, 1992; Rochester, 1990). These activities and deliverables have been built into a consolidated change model. This proposed model is represented diagrammatically in Figure 1 with a brief explanation of each phase. Two continuous activities have been added - the ongoing project management role that must be present for any change project and continual communication which is a key success factor underlying the change process (Finkin, 1992). Each phase of the model has been decomposed further into steps and activities along with the specific deliverables required at the end of each step.

The orientation phase would include understanding the change motivation, developing a change strategy and organizing the project. The change motivation would include a mandate, the purpose of the change, a cost/benefit analysis and specific terms of reference. The change strategy would include how quality would be measured, the project milestones, and how objectives would be measured. Organization aspects would include the establishment of a skilled change team and committed change sponsors. These activities are specifically focussed on the impact of the macro and micro changes and should not be confused with the project planning activities.

The second phase of the process is to Prepare for the Change by analysing the environment, announcing the change direction, developing the change workplan, creating pain and providing direction. In the analysis of the environment, the critical success factors for change should be identified along with a threat analysis. The change announcement should maximize communication effectiveness. The workplan should include detailed tasks and timings. The creating pain step should communicate the future position to a wider audience specifying clearly the need to make the change and its potential consequences. The final step in this phase is to provide direction. This would include strong communication of the goals and how they will be achieved.

In the third phase, the changes are implemented by piloting the change, introducing the new procedures, conducting training and finally rolling-out the change. If implementation at a pilot site is beneficial, one is chosen and implementation proceeds. Organizational aspects relating to reporting relation-

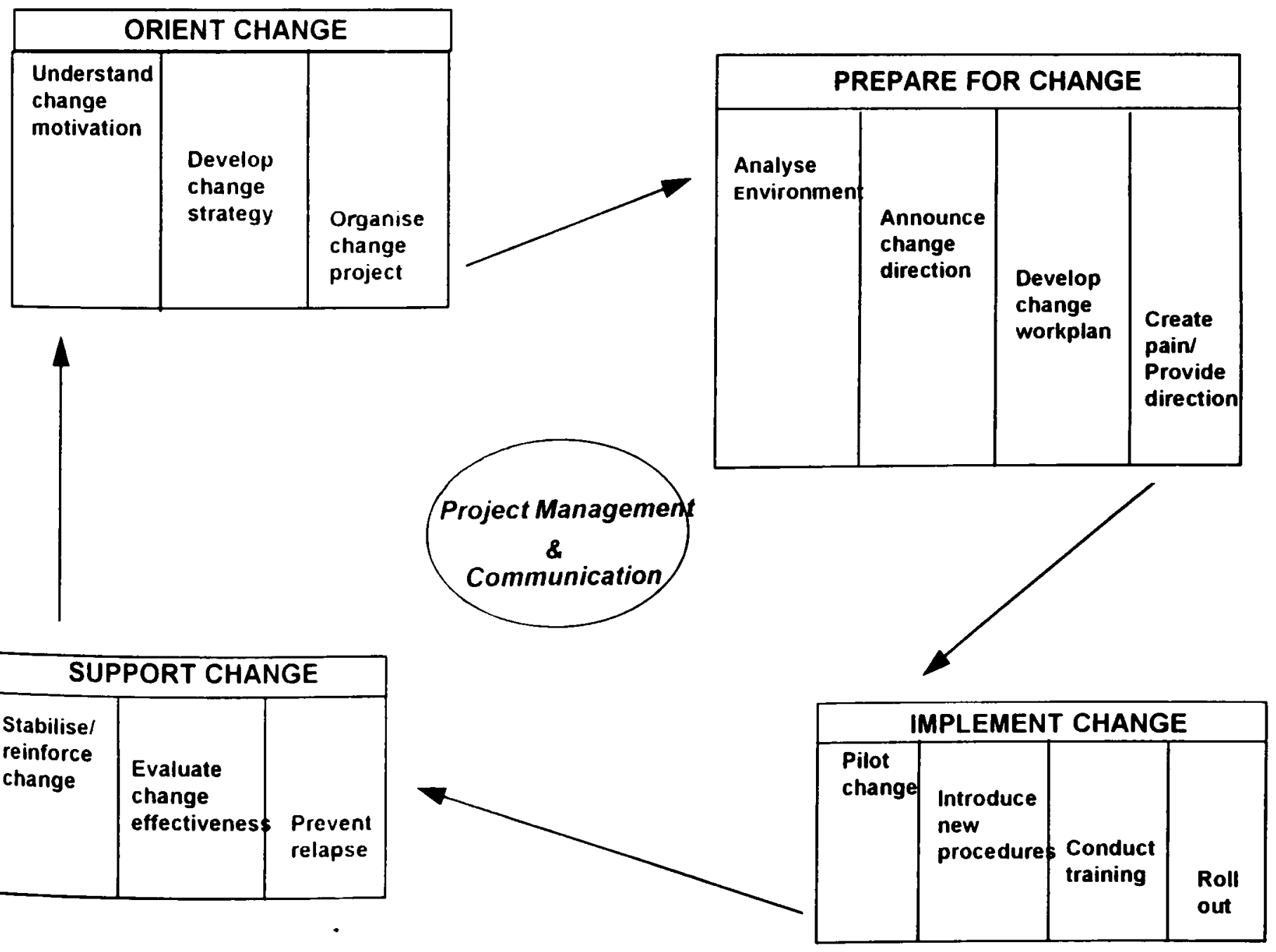

Figure 1 SDLC phases 
ships, job definitions, training schedules, working procedures and reward systems must be defined and communicated. Appropriate training should be completed and the implementation at all sites must be carried out using a roll-out plan.

In the final phase, full organizational support is offered with tasks that cover the stabilizing of the change, evaluating the effectivenenss of the change and the prevention of a relapse. In the stabilizing step, management openly commits itself to the change and procedures are fine-tuned or adjusted where necessary. The effectiveness of the change is evaluated by measuring acceptance and new behaviour and producing a formal report. To prevent a relapse into the old ways, regular review meetings should be held along with continual training and procedure reviews.

Although this study focusses on development projects in the IS industry, the derived change model could have general applicability.

\section{Change model mapped to the Systems Develop- ment Life Cycle (SDLC)}

The derived change model was compared with existing systems development lifecycle models. According to McComb \& Smith, 'the absence of rigid change management procedures in all phases of the SDLC (Systems Development Life Cycle) has been the downfall of many IS projects' (1991: 26). If the absence of a change management approach impedes user acceptance of the system then many of the planned benefits (and hence return on investment) may not be realised. This implies that there is a strong case to integrate a full Change Management programme into the SDLC or, alternatively, to run a Change Management programme in parallel with the SDLC.
The Systems Development Life Cycle (SDLC) is a model commonly used in the IS industry to identify the tasks neces. sary to plan and manage the implementation of a system. In Figure 2, each phase in a typical, generic SDLC (adapted from Herzog, 1991), is linked to the steps in the change model.

Mapping the change model onto the SDLC provides project managers with the extra change activities required in the overall project workplan.

\section{Conclusion}

Levine \& Rossmore claim that 'IT implementation is likely to be a complex and difficult process involving both the technical and social systems of an organization' (1993: 55). They feel that traditional methods fail to account for the human factors that impact IT implementation. With the increased use of approaches like Business Process Reengineering (BPR) to introduce organizational change, it is important that IS project team members are well versed in the application of change management (Benjamin \& Blunt, 1992).

While change is the means of growth, evolution and survival - the very essence of the learning organization - it needs to be managed to ensure that the organization and the individuals in it suffer less and profit more (Handy, 1995). Internal and external pressures demand that organizations introduce more effective ways of working. By their very nature, people resist change. Change involves letting go of something familiar and therefore poses a threat. The transition process between the old and new states must be carefully planned, with attention to overcoming that resistance, and creating an environment where sustained change is seen to be necessary by all participants. If the new state is not accepted, it can ultimately lead to a negation of the benefits the change was designed to yield. IT/IS are often used to support organizational change.

\begin{tabular}{|c|c|c|c|c|c|c|c|}
\hline $\begin{array}{l}\text { SDLC } \\
\text { Phases }\end{array}$ & $\begin{array}{l}\text { Information } \\
\text { (Systems) } \\
\text { Planning }\end{array}$ & $\begin{array}{l}\text { Preliminary } \\
\text { Systems } \\
\text { Design }\end{array}$ & $\begin{array}{l}\text { Detailed } \\
\text { Systems } \\
\text { Design }\end{array}$ & $\begin{array}{l}\text { Systems } \\
\text { Development }\end{array}$ & $\begin{array}{l}\text { System } \\
\text { Installation }\end{array}$ & $\begin{array}{l}\text { Post } \\
\text { Implementation } \\
\text { Review }\end{array}$ & Operation \\
\hline
\end{tabular}

\begin{tabular}{|c|c|c|c|c|c|c|}
\hline \multirow[b]{2}{*}{$\begin{array}{l}\text { Consolidated } \\
\text { Change } \\
\text { Model for IS }\end{array}$} & \multicolumn{6}{|c|}{ COMMUNICATION } \\
\hline & $\begin{array}{l}\text { Understand } \\
\text { Change } \\
\text { Motivation } \\
\text { Develop } \\
\text { Change } \\
\text { Strategy }\end{array}$ & \begin{tabular}{l} 
Organise \\
Change \\
Project \\
Analyse \\
Environment \\
Announce \\
Change \\
Direction \\
Create \\
Change \\
Workplan \\
\multicolumn{1}{c}{ Creat } \\
\end{tabular} & $\mid$\begin{tabular}{|l} 
\\
Pain \\
Provide Direction
\end{tabular} & $\begin{array}{l}\text { Introduce } \\
\text { New } \\
\text { Procedures } \\
\text { Conduct } \\
\text { Training } \\
\text { Pilot the } \\
\text { Change } \\
\text { Roll out } \\
\text { Change } \\
\text { Implement'n }\end{array}$ & $\begin{array}{l}\text { Stabilise/ } \\
\text { Reinforce } \\
\text { Change } \\
\text { Evaluate } \\
\text { Change } \\
\text { Effectiveness }\end{array}$ & $\begin{array}{l}\text { Prevent } \\
\text { Relapse }\end{array}$ \\
\hline
\end{tabular}

Figure 2 Measuring the success of IS change programmes: an exploratory study 
With the need to align IS goals more closely with corporate objectives, IS professionals need to be part of managing organizational change, and they must explore ways in which the transition process can be made more effective. The key areas of change management which have been identified include change planning, ensuring appropriate change leadership, creating a readiness for change, managing resistance to change, managing the transition, implementing and finally, evaluating the change.

By consolidating accepted approaches for managing organizational change, a change model is proposed for managing change associated with systems development. The model consists of four main phases: orientation, preparation, implementation and support. The orientation phase is where IS responds to the business need for change. It includes understanding the change motivation, developing a change strategy and organizing the change project. The second phase, preparing for change, involves analysing the environment, announcing the change direction, developing a change workplan, ensuring change readiness and providing a common direction. The implementation phase continues through the period when the computer system is being designed and developed. A pilot site may be used to test and improve upon the planned procedures. This phase covers introducing new procedures, conducting training and implementing the new system. The last phase, which is equally important as the first three, supports the change. It involves stabilizing or reinforcing the change, evaluating the system's effectiveness and ensuring that the new state remains permanent. To make the model operationally useful to IS practitioners, the authors have documented specific activities and deliverables to build into the development process. The derived change model was mapped on to a typical systems development life-cycle demonstrating where change activities could fit.

According to Duck,

'the fundamental job of leadership is to deal with the dynamics of change, the confluence and congruence of the forces that change unleashes, so that the company is better prepared to compete' (1993: 118).

The derived change model with its specific phases, tasks and deliverables could assist project managers in performing these duties. As Handy (1995) says, 'if we wish to enjoy more of the opportunity and less of the risk, we need to understand the changes better'.

\section{Acknowledgement}

The authors thank various colleagues for helpful ideas, and specifically Tony Hoffman for his insight and constructive criticism of earlier versions of the article.

\section{References}

Andersen Consulting. 1992. 'Change management systems'. Presentation material, July.

Benjamin, R.I. \& Blunt, J. 1992. 'Critical IT issues: the next ten years', Sloan Management Review: Summer: 7-19.

Blake, R.R., Mouton, J.S. \& McCanse, A.A. 1989. Change by design. Massachusetts: Addison-Wesley Publishing Company Inc.

Bridges, W. 1991. Managing transitions: making the most of change. Massachusetts: Addison-Wesley Publishing Company Inc.
Burke, W.W. 1982. Organization development: principles and practices. Glenview, Illinois: Scott, Foresman and Company: .

Burke, W.W. 1987. Organizational development: a normative view. Reading, Massachusetts: Addison-Wesley Publishing Company Inc.

Daft, R. 1983. Organizational theory and design. New York: West Publishing Company, pp.284-286.

Drucker, P.F. 1984. 'New templates for today's organizations', New Worlds for Business (Harvard Business Review Reprints), 1980; January/February.

Duberly, J. \& Burns, N. 1992. 'Implementing change at a British manufacturing company', Journal of Systems Management, February: $10-11 \& 34-38$.

Duck, J.D. 1993. 'Managing change: the art of balancing', Harvard Business Review, November/December.

Finkin, E.F. 1992. 'Structuring a successful turnaround', Journal of Business Strategy, July/August: 56-58.

Grundy, T. \& King, D. 1992. 'Using strategic planning to drive strategic change', Long Range Planning, February: 100-108.

Handy, C. 1995. The Age of unreason. London: Arrow Books.

Hersey, P. \& Blanchard, K. 1982. Management of organizational behaviour: utilizing human resources. Fourth Edition. Englewood Cliffs, New Jersey: Prentice-Hall Inc, pp.266-293.

Herzog, J.P. 1991. 'People: the critical factor in managing change', Journal of Systems Management, March: 6-11.

Human, P. \&Horwitz, F. 1992. On the edge: how South African companies cope with change. Cape Town: Juta \& Co., Limited.

Johnson, G. 1992. 'Managing strategic change - strategy, culture and action', International Journal of Strategic Management, Long range planning, February: $28-36$.

Kissler, G.D. 1991. The change riders: managing the power of change. Massachusetts, USA: Addison-Wesley Publishing.

Kolb, D.A. \& Frohman, A.L. 1991. 'An organizational development approach to consulting', Sloan Management Review, 12(1): 5164 .

Kumar, K. 1990. 'Post implementation evaluation of computerbased information systems: current practices', Communications of the $A C M, 33(2)$ : February.

Leontiades, M. 1980. Strategies for diversification and change. Boston: Little, Brown and Company.

Lester, T. 1992. 'Metamorphosis of the manager', Management Today, August: 73-76.

Levine, H.G. \& Rossmore, D.P. 1993. 'Diagnosing the human threats to information technology implementation', Journal of Management Information Systems, 10(2).

Lin, E. \& Ashcraft, P. 1990. 'A case of systems development in a hostile environment', Journal of Systems Management, April: 1114.

Mantei, M.M. \& Teorey, T.J. 1989. 'Incorporating behavioural techniques into the systems development life cycle', MIS Quarterly, September: $256-273$.

McComb, D. \& Smith, J.Y. 1991. 'System project failure', Journal of Information Systems Management, 8(1), Winter: 25-34.

McKersie, R.B. \& Walton, R.E. 1991. Organizational change: the corporation of the 1990s: information technology and organizational transformation. New York: Oxford University Press, pp.244-276.

Mohrman, A.M., Mohrman, S.A., Ledford, G.E., Cummings, T.G. \& Lawler, E.E. 1989. Large scale organizational change. California: Jossey Bass,

Nichol, R.L. 1992. 'Get middle managers involved in the planning process', Journal of Business Strategy, May/June: 26-32.

ODR. 1991. Managing Organizational Change (MOC), Research Review, Atlanta, USA: ODR. 
Orlikowski. W.J. \& Gash, D.C. 1992. Changing frames: understanding technological change in organizations. Massachusetts: Centre for Information Systems Research, Massachusetts Institute of Technology, Working Paper No 236: April.

Pearce, J.A. \& Robinson, R.B. 1989. Management. New York: McGraw-Hill Publishing Inc.

Quinn, J.B. \& Paquette, P.C. 1990. 'Technology in services: creating Organizational revolutions', Sloan Management Review, Winter : 67-78.

Rochester, J.B. 1990. 'Change management in information systems', I/S Anal yzer, 28(8): August.

Robbins, S.P. 1991. Organizational behavior: concepts, contm- versies, and applications. Fifth Edition. Englewood Cliffs, New Jersey: Prentice-Hall International Edition.

Schaffer, R.H. \& Thomson, H.A. 1992. 'Successful change programs begin with results', Harvard Business Review, JanuaryFebruary: 80-89.

Schein, E.H. 1980. Organizational psychology. Third Edition. Englewood Cliffs, New Jersey: Prentice-Hall Inc.

Spector, B.A. 1989. 'From bogged down to fired up: inspiring organ izational change', Sloan Management Review, Summer: 29-34.

Strebel, P. 1994. 'Choosing the right change path', California Management Review, 36(2): Winter. 